\title{
Who Breaks the Ice in Parent-Child Sexual Communication - Counselling Implications for Adolescent Health and Development?
}

\author{
Ojo Olubukola Olakunbi, Akintomide Akinjide G. \\ Department of Educational Foundations and Counselling \\ Obafemi Awolowo University, Nigeria
}

\begin{abstract}
The study investigated parent-child sexual communication in relation to parental education and age with the aim of determining if these variables can influence breaking of the 'culture of silence' associated with sexual communication between parents and adolescents. Survey research design was employed for the study. The population comprised all school going adolescents in Osun State, Nigeria. The sample used for the study comprised parents of 576 adolescent students selected from three Local Government Areas in Osun State, Nigeria using multistage sampling technique. Data were collected using a self developed questionnaire titled 'Parent-Child Sexual Communication Questionnaire (PCSCQ). The instrument was validated using experts' judgment. It was also tested for reliability. A reliability coefficient of 0.78 was obtained. Data were analyzed using chi-square, simple percentages and weighted average. The results revealed that parental educational attainment did not significantly influence sexual communication by the parents. It was also discovered that parents' age significantly influenced parent-child sexual communication and younger parents communicated sexual issues more than the older parents
\end{abstract}

\section{Introduction}

It has been established in literature that the social and cultural environment of most African communities are governed by 'culture of silence' when it comes to discussing sexual issues. This is because some topics are regarded as taboo in African culture [1]. The culture of silence created a communication gap between children and their parents in the family and it accounted for the reason why children were punished for misbehaviours and could not question their parents-especially the girls [2]. In Ghana for instance, if children wanted to "discuss sensitive issues with their parents", they had to pass it through a respectable elderly person [3]. The youths were neither allowed nor encouraged to associate with members of the opposite sex. Young people were naturally afraid to ask questions relating to sexual issues as they would be seen as "disrespectful" and "disobedient". Also, sexual issues were regarded as topics for adult discussions only. If a curious youth dared to ask a question about his or her sexuality, he or she would either be ignored or insulted (4). There was that misconception that children should not be educated on their sexuality. Religious beliefs also supported this view.

The dynamics of parent-child relationships and communications is greatly influenced by the culture and social environment in which they are. Parent-child communication on sexual issues remains a challenging issue in Nigeria as well as in many sub-Saharan African countries as the social milieu in many traditional communities still constrains such communication. Most adolescents do not seem to be comfortable talking about sexuality with their parents [5]. Initiating conversations about sexual issues may also be difficult for parents in such communities as they may be unsure as to how to approach such issues. They may equally doubt their competence in handling sexuality topics and the questions that may be raised by their adolescents or feel confused about the proper amount of information to offer [6]. An important issue in parent-adolescent communication is determining why parents fail to engage in meaningful discussions with their children. Research has suggested five classes of concerns that parents express about engaging in such conversations [9]: Not having the requisite knowledge/skills to explain things; Concern that the adolescent will not take the parent seriously; Concern with whether the communication will make a difference; Difficulties in finding the right time and place; and fear of encouraging sexual activity.Also, many parents forsake conversations because their adolescents tell them they already know what they need to know [3].

Overtime there had been increased sensitization programmes in African countries especially by international organizations to break the culture of silence as regards sexual communication. Such efforts include the intervention of UNFPA, USAID, COMPASS, Bill and Mellinda Gates, just to mention a few, in training school counsellors, teachers and health care providers on adolescent sexuality, health and development. The output of such effort had been the introduction of Family Life Education into the Nigerian school curriculum with the aim of improving adolescent reproductive health. 
Most of these efforts are targeted at the teachers, learners and other educational practitioner. With all the interventions heard about, a particular group which is very important appears to have been left out and these are the parents. Parents are the initial foundation of character formation and the primary agent of socialization. Considerable research has addressed whether parent's communication with their children about sex actually impacts adolescent sexual activity. Most of this research has been correlational in nature. The general finding in more recent studies has been that higher levels of parent-adolescent communication are associated with reduced sexual risk taking on the part of the adolescent. In addition, parent-adolescent communication has been found to moderate relationships between other variables and sexual activity. For example, peer norms have been found to be more influential for those adolescents who have not discussed sex with a parent as opposed to those who have [7]. Early studies tended to find no significant associations between parent-adolescent communication and risky sexual behaviour, whereas more recent studies have observed such links [8,9].

A small group of studies have found that higher levels of communication are associated with higher levels of adolescent sexual activity [10, 11]. These findings could be the result of parents deciding to talk with their children about sex after learning about or anticipating sexual activity on the part of the children (so that behaviour influences communication rather than vice versa). Or, it could be that such discussions encourage subsequent adolescent sexual risk taking. Whatever has been established in literature, it is not known if the increased sensitization efforts have been making impact in reducing the culture of silence on sexual issues in Nigerian communities especially among the Yorubas. The fact that parents are not the primary focus of many interventions makes it important to determine the level at which parents communicate sexual issues with their children and also to find out if the younger generation of parents communicate more with their children. The findings from this study can form the baseline of any interventional effort targeted at parents in improving their communication with their children on sexual issues.

One of the dimensions that were pointed at by [12] as being important in general communication research was the perceived expertise of the source of the message. Expertise refers to knowledge, expert status, and familiarity with the topic. Expertise might come with years of experience. Perhaps, old parents would be expected to have more experiences about many things in life that could invariably help them to communicate well with their children. It is worth noting also that expertise might equally come with education. Education is a very strong tool for socialization. Someone might be of age but not educated, but it would be expected that the more educated a person is, the more exposed he or she should be. Exposure through education should involve the acquisition of effective communication skills. If these assertions are valid, then parental level of educational attainment should invariably influence their expertise as well as their communication skills on many issues (sexual issues inclusive). This research would like to validate this assertion by finding out the correlation between parental educational attainment, age and parentchild sexual communication. On the basis of this, two hypotheses were postulated for the study. They are: Hypothesis 1:

Parental educational attainment does not significantly influence parent-child sexual communication

Hypothesis 2:

Age of Parents does not significantly influence parent child sexual communication.

\section{Methodology}

Survey research design was employed for the study. The population for this study consisted of all the adolescent students in Osun State secondary schools. The sample comprised 576 students selected using multistage sampling technique. The first stage involved a random selection of three Local Government Areas LGAs (Ife Central, Ayedaade and Olorunda) from the existing thirty LGAs in the state. Four schools were randomly selected from each of the three LGAs. Afterwards, 50 students whose parents could read and write were selected among students in Senior Secondary classes $(1-3)$ from each of the schools using sex and class as strata. A total sample of 600 was selected but 551 of them returned the instrument completed correctly. Data were collected using a self developed questionnaire titled 'Parent-Child Sexual Communication Questionnaire' (PCSCQ). The first section of the instrument elicited information on Parents' demographic data while the other section elicited information on nature and frequency of sexual communication. The instrument was validated using experts judgment. It was also tested for reliability. A reliability coefficient of 0.78 was obtained. A copy of the instrument was enclosed in an envelop, sent and retrieved from the respondents through the selected students. Data were analyzed using chi-square, simple percentages and weighted average.

\section{Results}

\section{Hypothesis 1:}

Parental educational attainment does not significantly influence parent-child sexual communication.

To test hypothesis I, parental educational qualification on three levels (no formal education and primary, secondary and tertiary education) was correlated with parents' sexual communication using chi-square (see 
Table 1 under appendix I). The result revealed that there was no significant relationship between parental educational attainment and sexual communication $(\chi 2=$ $3.46, \mathrm{p}>0.05)$. The table showed that a chi-square value of 3.46 was obtained at $p=0.484$. Since the $p$ value is greater than 0.05 , the null hypothesis was upheld. It could be concluded that parental educational attainment did not significantly influence sexual communication by the parents.

Out of the 253 that had tertiary education, only 86 $(33.99 \%)$ of them were high sexual communicators, 141 (representing 55.73\%) were moderate sexual communicators while the remaining 26 respondents $(10.78 \%)$ were low communicators. Of all the respondents, 231 had secondary education, 88 of them were high sexual communicators, 115 which is equivalent to $49.78 \%$ were moderate sexual communicators and $28 \quad(12.12 \%)$ were low communicators. Furthermore, from the 67 parents with no formal education or maximum of primary education, 41 representing $61.20 \%$ were moderate sexual communicators while 21 out of the 67 were high communicators. This showed that the parents' educational attainment did not significantly influence their sexual communication.

\section{Hypothesis 2:}

Age of Parents does not significantly influence parentchild sexual communication.

To test hypothesis 2, parents' age was put into four categories and correlated with their communication on sexual issues using chi-square analysis (see Table 2). The result showed that there was no significant relationship between parents' age and sexual communication $(\chi 2=15.01, \mathrm{p}<0.05)$, Table 2 showed that a chi-square value of 15.01 was obtained at $\mathrm{p}=$ 0.029 . Since the $p$ value is less than 0.05 , the null hypothesis was rejected. Hence, it could be concluded that parents' age significantly influenced parent-child sexual communication. The level of significance tilted towards the younger parents. Out of 100 parents that were below 40 years of age, 74 of them were high sexual communicators. The same thing went for parents between ages 41 and 50 . They were 338 in this category out of which 252 , representing $74.51 \%$ of the group and $45.74 \%$ of the whole respondents, were high communicators.

Older parents (60 years and above) constituted $4.90 \%$ of the sample (27 out of 551), 37.04\% of them were moderate communicators, $25.92 \%$ of them were low communicators and the remaining $37.04 \%$ were high communicators. It therefore showed that younger parents communicated sexual issues than the older parents.

\section{Discussion and Conclusion}

It can be concluded from the findings above that parents' educational qualifications did not significantly influence their sexual communication. It was discovered that even parents whose educational attainment was just secondary education averagely communicated sexual issues more than those with tertiary educational qualifications. On the moderate level of communication, little difference was observed between these two sets of parents.

There could be some reasons why parents with less educational attainments would communicate more than those with higher qualifications. Some parents, who had no opportunity of attaining higher educational qualifications because they dropped out of school due to teenage pregnancy or similar occurrences, would rather want to prevent their children from the same pit fall. They would rather speak to them from time to time on sexual issues. Another reason that could be adduced to these differences is that some parents who had tertiary education and are gainfully employed could be preoccupied with the demands of their jobs at the expense of parental care and attention that the children deserve. It was observed from the study that younger parents, especially parent within the age range of below 40 up to 50 years, were better sexual communicators than the older ones. To the researchers, the reason was not far fetched; most of these young parents grew in the same 'new' generation with their children. They were familiar with the current trends in adolescent development; they were equally familiar with the infiltration of the western culture as well as technological advancements. Some of the older generations were seen by the adolescents as being out of touch with current lifestyles and pressures, and the adolescents therefore undermined their expertise on sexual issues. This assertion was strongly supported by [13]. Most of the parents in the category of older generation are regarded as belonging to the 'old school' by the adolescents, but the young parents especially those that were less than 50 years, which constituted the higher sexual communicators, belong to the 'new generation', or the 'new school'. They knew what is in vogue and could equally communicate with their children in line with what is obtainable in the contemporary age.

Based on the findings of this study, it is recommended that Government as well as school Counsellors, with the assistance of donor agencies, should organize adult training programmes on sex education. Mass media should also be encouraged to be actively involved in sensitizing parents on the need to be involved in sex education of their children. 


\section{References}

[1] Action Health Incorporated (AHI), (2003), Comprehensive sexuality education: Trainers' resource manual, Lagos: AHI.

[2] Brocato, Vanessa, and Angela Dwamena-Aboagye (2007). Violence Against Women \& HIV/AIDS. Eds. Yvette Amissah, et al. Achimota: The Ark Foundation Ghana.

[3] Oppong, Christine, M. Yaa P. A. Oppong, and Irene K. Odotei, (2006). Sex and Gender in an Era of AIDS: Ghana at the turn of the millennium. Accra: Sub-Saharan Publishers.

[4] Osei (2009). Sex Education in Ghanaian Society: The Skeleton in the Cupboard. Retrieved on 28/01/2010 from http://www.ashesi.org/ACADEMICS/WRITING_CENT RE/2009_Writing/09_Osei_essay.pdf.

[5] Carrera, M.A (2003) Parents and their children Learning about Sexuality. The Children's Aid Society. New York. Retrieved on 3/4/2008 from http:// www.advocatesforyouth.org/parents/experts/ carerra.htm.

[6] Akinwale, O. P., Omotola, B. D., Manafa, O.U., Adeneye, A.K., Idowu, E.T., Sulyman, M.A. and Adewale, D. B. (2006), An assessment of parent-child communication on sexuality in Lagos, Nigeria.

[7] Whitaker, D. J. and Miller, K. S. (2000), Parentadolescent discussions about sex and condoms, Journal of Adolescent Research 15, 251- 273.

[8] Jaccard, J. \& Dittus, P. (1993), Parent-adolescent communication about premarital pregnancy, Families in Society 74, 329-343.

[9] Jaccard, J., Dodge, T. \& Dittus, P. (2002), Parentadolescent communication about sex and birth control: A conceptual framework. In Out in the open: Parent-teen communication about sexuality, New Directions in Child and Adolescent Development, ed. S. Feldman and D. A. Rosenthal. San Francisco: Jossey-Bass.

[10] Darling, C. A. \& Hicks, M. W. (1982), Parental influences on adolescent sexuality: Implication for parents as educators, Journal of Youth and Adolescence 11:231-245.

[11] Widner, E. D. (1997), Influence of older siblings on initiation of sexual intercourse, Journal of Marriage and the Family 59, 928-938.
[12] Metts, S. and Jaccard, J. (2002), Sexual communication - couple relationships, parent-child Relationships, Retrieved on 20/08/2008 at http://family.jrank.org/pages/1500/sexualcommunication -parent-child-relationships.html.

[13] Moore S. \& Rosenthal D. (2006), Sexuality in adolescence; current trends, London, Routledge Taylor \&Francis Group. 


\section{Appendix I}

Table 1. Chi-square analysis of Parents' educational attainment and sexual communication

\begin{tabular}{|c|c|c|c|c|c|c|c|}
\hline \multirow{2}{*}{$\begin{array}{c}\text { Parents' Educational } \\
\text { Attainment }\end{array}$} & \multicolumn{3}{|c|}{ Parents' Sexual Communication } & \multirow[b]{2}{*}{ Total } & \multirow{2}{*}{$\mathrm{df}$} & \multirow{2}{*}{$\chi^{2}$} & \multirow{2}{*}{$\mathrm{p}$} \\
\hline & Low & Moderate & High & & & & \\
\hline $\begin{array}{l}\text { No Formal Education to } \\
\text { Primary Education }\end{array}$ & $\begin{array}{c}5 \\
(7.5 \%) \\
\end{array}$ & $\begin{array}{c}41 \\
(61.20 \%)\end{array}$ & $\begin{array}{c}21 \\
(31.30 \%)\end{array}$ & $\begin{array}{c}67 \\
(100 \%)\end{array}$ & \multirow{4}{*}{4} & \multirow{4}{*}{3.46} & \multirow{4}{*}{0.484} \\
\hline Secondary Education & $\begin{array}{c}28 \\
(12.12 \%) \\
\end{array}$ & $\begin{array}{c}115 \\
(49.78 \%) \\
\end{array}$ & $\begin{array}{c}88 \\
(38.10 \% \\
\end{array}$ & $\begin{array}{c}231 \\
(100 \%)\end{array}$ & & & \\
\hline Tertiary & $\begin{array}{c}26 \\
(10.78 \%)\end{array}$ & $\begin{array}{c}141 \\
(55.73 \%)\end{array}$ & $\begin{array}{c}86 \\
(33.99 \%)\end{array}$ & $\begin{array}{c}253 \\
(100 \%)\end{array}$ & & & \\
\hline Total & 59 & 297 & 195 & 551 & & & \\
\hline
\end{tabular}

Table 2. Chi-square analysis of Parents' age and sexual communication

\begin{tabular}{|c|c|c|c|c|c|c|c|}
\hline \multirow{2}{*}{ Parents' Age range } & \multicolumn{3}{|c|}{ Parents' Sexual Communication } & \multirow[b]{2}{*}{ Total } & \multirow{2}{*}{$\mathrm{df}$} & \multirow{2}{*}{$\chi^{2}$} & \multirow{2}{*}{$\mathrm{p}$} \\
\hline & Low & Moderate & High & & & & \\
\hline Below 40yrs & $\begin{array}{c}6 \\
(6.00 \%)\end{array}$ & $\begin{array}{c}20 \\
(20.00 \%)\end{array}$ & $\begin{array}{c}74 \\
(74.00 \%)\end{array}$ & $\begin{array}{c}100 \\
(100 \%)\end{array}$ & \multirow{5}{*}{6} & \multirow{5}{*}{15.01} & \multirow{5}{*}{0.029} \\
\hline $41-50 \mathrm{yrs}$ & $\begin{array}{c}6 \\
(1.72 \%) \\
\end{array}$ & $\begin{array}{c}80 \\
(23.67 \%) \\
\end{array}$ & $\begin{array}{c}252 \\
(74.51 \%) \\
\end{array}$ & $\begin{array}{c}338 \\
(100 \%) \\
\end{array}$ & & & \\
\hline $51-60 y r s$ & $\begin{array}{c}5 \\
(5.81 \%)\end{array}$ & $\begin{array}{c}16 \\
(18.61 \%)\end{array}$ & $\begin{array}{c}65 \\
(75.58 \%)\end{array}$ & $\begin{array}{c}86 \\
(100 \%)\end{array}$ & & & \\
\hline Above $60 y r s$ & $\begin{array}{c}7 \\
(25.92 \%)\end{array}$ & $\begin{array}{c}10 \\
(37.04 \%)\end{array}$ & $\begin{array}{c}10 \\
(37.04 \%)\end{array}$ & $\begin{array}{c}27 \\
(100 \%)\end{array}$ & & & \\
\hline Total & 24 & 126 & 401 & 551 & & & \\
\hline
\end{tabular}

